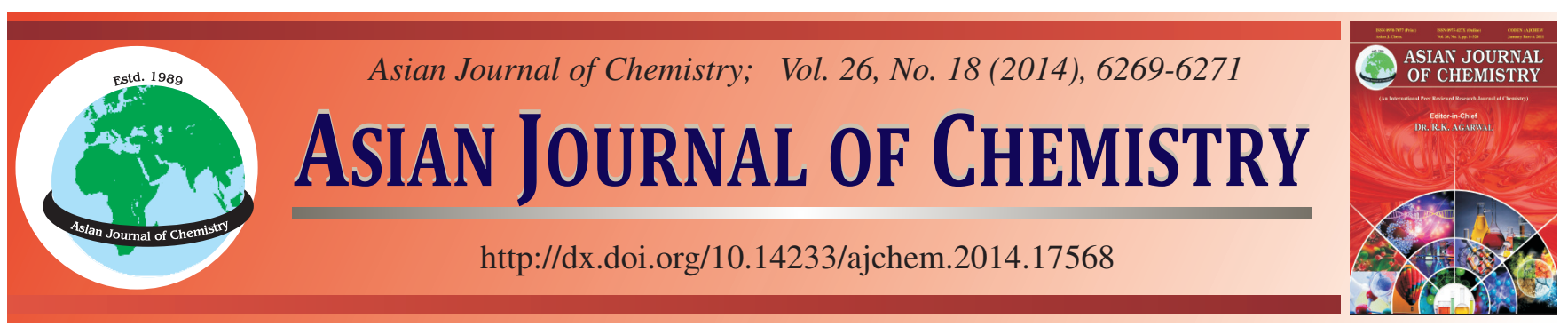

\title{
Synthesis and Characterization of Salamo-Type Bisoxime Compounds Based on 2-Hydroxy-4-methoxybenzaldehyde and Bis(aminooxy)alkane
}

Li WANG ${ }^{*}$, Wei-Min Zhou, GANG Li and YANG Zhang

School of Chemical and Biological Engineering, Lanzhou Jiaotong University, Lanzhou 730070, P.R. China

*Corresponding author: E-mail: wangli_78@126.com; kkil615@yahoo.com.cn

Received: 7 March 2014;

Accepted: 15 May 2014;

Published online: 1 September 2014;

AJC-15896

Three new Salamo-type bisoxime compounds $\mathrm{H}_{2} \mathrm{~L}^{1}-\mathrm{H}_{2} \mathrm{~L}^{3}$ have been synthesized from 2-hydroxy-4-methoxybenzaldehyde and $1,5-$
bis(aminooxy)pentane, 1,6-bis(aminooxy)hexane or 1,9-bis(aminooxy)nonane in hot ethanol medium, respectively and characterized by
elemental analysis, IR and ${ }^{1} \mathrm{H}$ NMR spectroscopy.
Keywords: Salamo-type compound, Synthesis, Characterization.

\section{INTRODUCTION}

Particular attention has been paid in recent years to the synthesis, characterization and application of Salen-type compounds ${ }^{1}$. The new Salen-type bisoxime compounds have very important value that they are widely used in catalytic domain $^{2}$, medical field ${ }^{3,4}$, analytical chemistry ${ }^{5}$, material world $^{6,7}$, etc. So we devoted to design and synthesis of a series of new Salamo-type bisoxime compounds which have farreaching significance. In the present study we have designed and synthesized three new Salamo-type bisoximes, named as 5,5'-dimethoxy-2,2'-[(pentane-1,5-diyldioxy) bis-(nitrilomethylidyne) ]diphenol $\left(\mathrm{H}_{2} \mathrm{~L}^{1}\right), 5,5^{\prime}$-dimethoxy-2,2'-[(hexane1,6-diyldioxy)bis(nitrilo-methylidyne)]diphenol $\left(\mathrm{H}_{2} \mathrm{~L}^{2}\right)$ and 5,5'-dimethoxy-2,2'-[(nonane-1,9-diyldioxy)bis-(nitrilomethylidyne)]diphenol $\left(\mathrm{H}_{2} \mathrm{~L}^{3}\right)$.

\section{EXPERIMENTAL}

2-Hydroxy-4-methoxybenzaldehyde ( $\geq 99 \%), 1,5$ dibromopentane (97\%), 1,6- dibromohexane (97\%) and 1,9dibromononane $(97 \%)$ were purchased and used without further purification. Other reagents were analytical pure grade and purchased from Tianjin Chemical Reagent Factory. The others are the same as literature ${ }^{8,9}$.

General procedure: Synthetic route to Salamo-type bisoxime compounds $\mathrm{H}_{2} \mathrm{~L}^{1}-\mathrm{H}_{2} \mathrm{~L}^{3}$ are shown in Fig. 1-4. 1,5bis(aminooxy)pentane, 1,6-bis(aminooxy)hexane or 1,9bis(aminooxy)nonane were synthesized according to an analogous method reported earlier ${ }^{7-9}$.

Preparation of 5,5'-dimethoxy-2,2'-[(pentane-1,5diyldioxy)bis(nitrilomethylidyne)]diphenol $\left(\mathbf{H}_{2} \mathbf{L}^{1}\right)$ : To an ethanolic solution $(10 \mathrm{~mL})$ of 2-hydroxy-4-methoxybenzaldehyde (304.3 mg, $2 \mathrm{mmol}$ ) was added an ethanolic solution (6 mL) of 1,5-bis(aminooxy)pentane (134.2 mg, $1 \mathrm{mmol}$ ). The reaction mixture was stirred at $328 \mathrm{~K}$ for $5 \mathrm{~h}$. The formed precipitate was separated by filtration and washed successively with ethanol $/ n$-hexane (1:4). The product was dried under vacuum to obtain white title compound $\mathrm{H}_{2} \mathrm{~L}^{1}$.

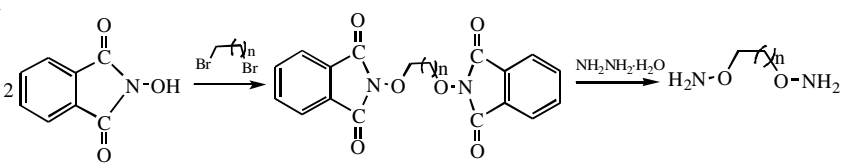

Fig. 1. Synthetic route to bis(aminooxy)alkane. $\mathrm{H}_{2} \mathrm{~L}^{1}: \mathrm{n}=4 ; \mathrm{H}_{2} \mathrm{~L}^{2}: \mathrm{n}=5$; $\mathrm{H}_{2} \mathrm{~L}^{3}: \mathrm{n}=8$

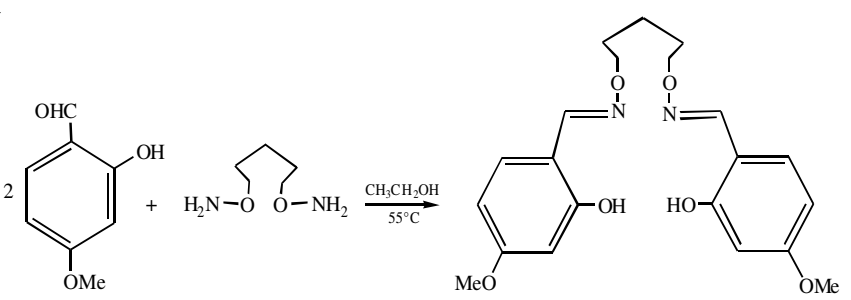

Fig. 2. Synthetic route to the Salamo-type bisoxime compound $\mathrm{H}_{2} \mathrm{~L}^{1}$

Preparation of 5,5'-dimethoxy-2,2'-[(hexane-1,6diyldioxy)bis(nitrilomethylidyne)]diphenol $\left(\mathbf{H}_{2} \mathbf{L}^{2}\right)$ : To an ethanolic solution $(6 \mathrm{~mL})$ of 2-hydroxy-4-methoxybenzaldehyde (194.5 mg, $1.28 \mathrm{mmol}$ ) was added an ethanolic solution (10 mL) of 1,6-bis(aminooxy)hexane (81.1 mg, $0.64 \mathrm{mmol}$ ). The reaction mixture was stirred at 328-333 $\mathrm{K}$ for $6 \mathrm{~h}$. The formed precipitate was separated by filtration and washed 
successively with ethanol $/ n$-hexane (1:4). The product was dried under vacuum to obtain white title compound $\mathrm{H}_{2} \mathrm{~L}^{2}$.

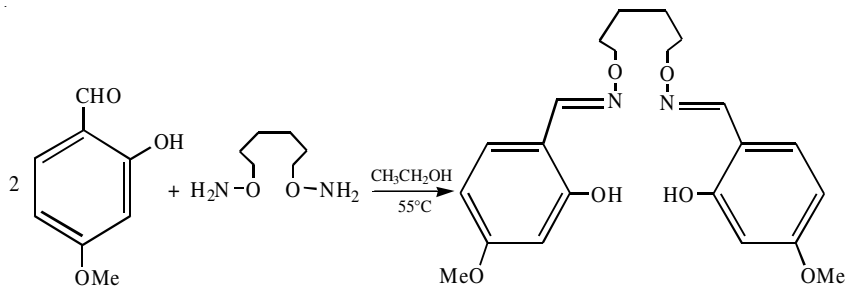

Fig. 3. Synthetic route to the Salamo-type bisoxime compound $\mathrm{H}_{2} \mathrm{~L}$

Preparation of 5,5'-dimethoxy-2,2'-[(nonane-1,9diyldi-oxy)bis(nitrilomethylidyne)]diphenol $\left(\mathbf{H}_{2} \mathbf{L}^{3}\right)$ : To an ethanolic solution $(5 \mathrm{~mL})$ of 2-hydroxy-4-methoxybenzaldehyde (159.5 mg, $1.05 \mathrm{mmol}$ ) was added an ethanolic solution ( $5 \mathrm{~mL}$ ) of 1,9-bis(aminooxy)nonane (99 $\mathrm{mg}, 0.52 \mathrm{mmol}$ ). The reaction mixture was stirred at $328 \mathrm{~K}$ for $8 \mathrm{~h}$. The formed precipitate was separated by filtration under reduced pressure and washed successively with ethanol $/ n$-hexane (1:4). The product was dried under vacuum to obtain white powder compound $\mathrm{H}_{2} \mathrm{~L}^{3}$.

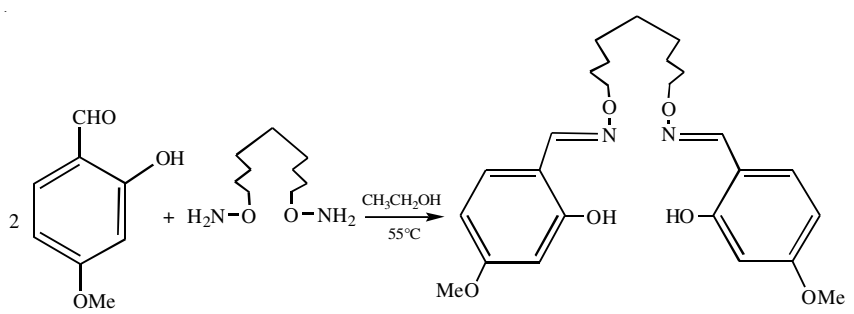

Fig. 4. Synthetic route to the Salamo-type bisoxime compound $\mathrm{H}_{2} \mathrm{~L}^{3}$

\section{RESULTS AND DISCUSSION}

Three Salamo-type bisoxime compounds $\mathrm{H}_{2} \mathrm{~L}^{1}-\mathrm{H}_{2} \mathrm{~L}^{3}$ have been synthesized with good yields and the compositions are confirmed by elemental analyses, IR, UV-visible and ${ }^{1} \mathrm{H}$ NMR spectroscopy.

Physico-chemical property: The colour, yields, melting points and elemental analytical results of the synthesized Salamo-type bisoxime compounds $\mathrm{H}_{2} \mathrm{~L}^{1}-\mathrm{H}_{2} \mathrm{~L}^{3}$ are presented in Table-1. Their compositions agree with the formulae. All the compounds are stable in air and soluble in chloroform, tetrahydrofuran, acetone, DMF, DMSO and hot methanol or ethanol, insoluble in $n$-hexane. In addition, $\mathrm{H}_{2} \mathrm{~L}^{1}$ are soluble in dichloromethane and acetonitrile, but $\mathrm{H}_{2} \mathrm{~L}^{3}$ are insoluble in dichloromethane and just soluble in hot acetonitrile. $\mathrm{H}_{2} \mathrm{~L}^{1}$ and $\mathrm{H}_{2} \mathrm{~L}^{3}$ are easy to be dissolved in ethyl ether and acetic ether, but $\mathrm{H}_{2} \mathrm{~L}^{2}$ are difficult to be dissolved in ethyl ether, simultaneously, it can't be dissolved in acetic ether.

IR spectra: The most important IR spectral data for Salamo-type bisoxime compounds $\mathrm{H}_{2} \mathrm{~L}^{1}-\mathrm{H}_{2} \mathrm{~L}^{3}$ are given in Table-2. In the IR spectrum of Salamo-type bisoxime compound $\mathrm{H}_{2} \mathrm{~L}^{1}, 2950$ and $2879 \mathrm{~cm}^{-1}$ are the weak absorption peaks for both antisymmetric and symmetric stretching vibration absorption of C-H bond of methylene. In the IR Spectrum of Salamo-type bisoxime compound $\mathrm{H}_{2} \mathrm{~L}^{2}$, it contains $\mathrm{v}_{\mathrm{O}-\mathrm{H}}$ bond, but no corresponding peaks were observed near 3600 $\mathrm{cm}^{-1}$, while at 3169 and $3072 \mathrm{~cm}^{-1}$, there exists strong broad absorption peaks, indicating that Salamo-type bisoxime compound $\mathrm{H}_{2} \mathrm{~L}^{2}$ may have freedom intramolecular hydrogen bond $(\mathrm{OH} \cdots \mathrm{N}$ and $\mathrm{OH} \cdots \mathrm{O})$ and at 2945 and $2879 \mathrm{~cm}^{-1}$, the weak absorption peak can be attributed to the antisymmetric and symmetric stretching vibration absorption of $\mathrm{C}-\mathrm{H}$ bond from methylene. Similarly, infrared spectrum of Salamo-type bisoxime compound $\mathrm{H}_{2} \mathrm{~L}^{3}$ contains broad absorption peak at 3431 and $3161 \mathrm{~cm}^{-1}$ also shows that the Salamo-type bisoxime compound $\mathrm{H}_{2} \mathrm{~L}^{3}$ may contain an intramolecular hydrogen bond $(\mathrm{OH} \cdots \mathrm{N})$. The anti-symmetric and symmetric methyl stretching vibration absorption peak of C-H bond presented at 2989 and $2852 \mathrm{~cm}^{-1}$ which was very weak.

Meanwhile, the characteristic $\mathrm{C}=\mathrm{N}$ stretching bands of the Salamo-type bisoximes $\mathrm{H}_{2} \mathrm{~L}^{1}-\mathrm{H}_{2} \mathrm{~L}^{3}$ appear at $1609-1606$ $\mathrm{cm}^{-1}$, respectively ${ }^{10}$. And the Ar-O stretching bands occur at 1225,1223 and $1211 \mathrm{~cm}^{-1}$ for the Salamo-type bisoximes $\mathrm{H}_{2} \mathrm{~L}^{1}$ $\mathrm{H}_{2} \mathrm{~L}^{3}$, indicating that 2-hydroxy-4-methoxybenzaldehyde has been condensated with 1,5-bis(aminooxy)penpane, 1,6bis(aminooxy)hexane or 1,9-bis(aminooxy)nonane, respectively and formed new Salamo-type bisoximes ${ }^{11}$. In the 1572$1441 \mathrm{~cm}^{-1}$ region, the observed bands were attributed to aromatic $\mathrm{C}=\mathrm{C}$ vibrations. IR spectral results of the Salamo-type bisoximes further confirmed the accuracy of the consequence. So in this research we have successfully synthesized the target compounds, $\mathrm{H}_{2} \mathrm{~L}^{1}, \mathrm{H}_{2} \mathrm{~L}^{2}$ and $\mathrm{H}_{2} \mathrm{~L}^{3}$.

${ }^{1}$ H NMR spectra: The ${ }^{1} \mathrm{H}$ NMR spectral data of the Salamotype bisoxime compounds $\mathrm{H}_{2} \mathrm{~L}^{1}-\mathrm{H}_{2} \mathrm{~L}^{3}$ in the solvent of $\mathrm{CDCl}_{3}$ are shown in Table-3. The ${ }^{1} \mathrm{H}$ NMR analytical results are

\begin{tabular}{|c|c|c|c|c|c|c|c|c|}
\hline \multirow{3}{*}{ Compound } & \multicolumn{8}{|c|}{$\begin{array}{l}\text { TABLE-1 } \\
\text { COLOUR, YIELDS, MELTING POINTS AND ANALYTICAL DATA OF } \\
\text { SYNTHESIZED SALAMO-TYPE BISOXIME COMPOUNDS } \mathrm{H}_{2} \mathrm{~L}^{1}-\mathrm{H}_{2} \mathrm{~L}^{3}\end{array}$} \\
\hline & \multirow{2}{*}{ Colour } & \multirow{2}{*}{ m.p. $(\mathrm{K})$} & \multirow{2}{*}{ Yield (\%) } & \multirow{2}{*}{ m.f. } & \multirow{2}{*}{ m.w. } & \multicolumn{3}{|c|}{ Elemental analysis (\%): Found (Calcd.) } \\
\hline & & & & & & $\mathrm{C}$ & $\mathrm{H}$ & $\mathrm{N}$ \\
\hline $\mathrm{H}_{2} \mathrm{~L}^{1}$ & White & $349-350$ & 51.8 & $\mathrm{C}_{21} \mathrm{H}_{26} \mathrm{~N}_{2} \mathrm{O}_{6}$ & 402.44 & $62.79(62.67)$ & $6.68(6.51)$ & $6.83(6.96)$ \\
\hline $\mathrm{H}_{2} \mathrm{~L}^{2}$ & White & $349-350$ & 46.5 & $\mathrm{C}_{22} \mathrm{H}_{28} \mathrm{~N}_{2} \mathrm{O}_{6}$ & 416.47 & $63.78(63.45)$ & $6.91(6.78)$ & $6.68(6.73)$ \\
\hline $\mathrm{H}_{2} \mathrm{~L}^{3}$ & White & $465-467$ & 32.3 & $\mathrm{C}_{25} \mathrm{H}_{34} \mathrm{~N}_{2} \mathrm{O}_{6}$ & 458.55 & $65.63(65.48)$ & $7.79(7.47)$ & $6.07(6.11)$ \\
\hline
\end{tabular}

TABLE-2

KEY IR BANDS $\left(\mathrm{cm}^{-1}\right)$ FOR THE SALAMO-TYPE BISOXIME COMPOUNDS $\mathrm{H}_{2} \mathrm{~L}^{1}-\mathrm{H}_{2} \mathrm{~L}^{3}$

\begin{tabular}{cccccc}
\hline Compound & $v(\mathrm{O}-\mathrm{H})$ & $v\left(\mathrm{CH}_{2}\right)$ & $v(\mathrm{C}=\mathrm{N})$ & $v(\mathrm{C}=\mathrm{C})_{\text {benzene ring }}$ & $v(\mathrm{Ar}-\mathrm{O})$ \\
\hline $\mathrm{H}_{2} \mathrm{~L}^{1}$ & 3435 & 2950,2879 & 1606 & $1568,1506,1467$ & 1225 \\
$\mathrm{H}_{2} \mathrm{~L}^{2}$ & 3443 & 2945,2879 & 1626 & $1572,1505,1464$ & 1223 \\
$\mathrm{H}_{2} \mathrm{~L}^{3}$ & 3431 & 2989,2852 & 1609 & $1568,1505,1441$ & 1211 \\
\hline
\end{tabular}




\begin{tabular}{|c|c|}
\hline & $\begin{array}{l}\text { TABLE-3 } \\
\text { THE }{ }^{1} \mathrm{H} \text { NMR DATA FOR THE SALAMO-TYPE BISOXIME COMPOUNDS } \mathrm{H}_{2} \mathrm{~L}^{1}-\mathrm{H}_{2} \mathrm{~L}^{3}\end{array}$ \\
\hline Compound & ${ }^{1} \mathrm{H}$ NMR (400 MHz, $\left.\mathrm{CDCl}_{3}, \delta / \mathrm{ppm}\right)$ \\
\hline $\mathrm{H}_{2} \mathrm{~L}^{1}$ & $\begin{array}{l}2.79\left(\mathrm{~s}, 6 \mathrm{H}, \mathrm{CH}_{2}\right), 4.41\left(\mathrm{~s}, 10 \mathrm{H}, \mathrm{CH}_{2}-\mathrm{O}, \mathrm{CH}_{3}-\mathrm{O}\right), 6.46(\mathrm{~d}, J=2.8 \mathrm{~Hz}, 2 \mathrm{H}, \mathrm{PhH}), 6.47(\mathrm{dd}, J=8.4 \mathrm{~Hz}, 2.6 \mathrm{~Hz}, 2 \mathrm{H}, \mathrm{PhH}), 7.04(\mathrm{~d}, J= \\
8.8 \mathrm{~Hz}, 2 \mathrm{H}, \mathrm{PhH}), 8.17(\mathrm{~s}, 2 \mathrm{H}, \mathrm{N}=\mathrm{CH}), 9.94(\mathrm{~s}, 2 \mathrm{H}, \mathrm{OH})\end{array}$ \\
\hline $\mathrm{H}_{2} \mathrm{~L}^{2}$ & $\begin{array}{l}2.13\left(\mathrm{t}, J=6.6 \mathrm{~Hz}, 2 \mathrm{H}, \mathrm{CH}_{2}\right), 3.64\left(\mathrm{~s}, 6 \mathrm{H}, \mathrm{CH}_{2}\right), 4.26\left(\mathrm{t}, J=6.20 \mathrm{~Hz}, 10 \mathrm{H}, \mathrm{CH}_{2}-\mathrm{O}, \mathrm{CH}_{3}-\mathrm{O}\right), 6.46(\mathrm{~d}, J=2.4 \mathrm{~Hz}, 2 \mathrm{H}, \mathrm{PhH}), 6.50(\mathrm{~s}, J \\
=2.4 \mathrm{~Hz}, 2 \mathrm{H}, \mathrm{PhH}), 7.06(\mathrm{~S}, 2 \mathrm{H}, \mathrm{PhH}), 8.09(\mathrm{~s}, 2 \mathrm{H}, \mathrm{N}=\mathrm{CH}), 10.02(\mathrm{~s}, 2 \mathrm{H}, \mathrm{OH})\end{array}$ \\
\hline $\mathrm{H}_{2} \mathrm{~L}^{3}$ & $\begin{array}{l}2.02\left(\mathrm{t}, J=6.6 \mathrm{~Hz} 2 \mathrm{H}, \mathrm{CH}_{2}\right), 3.81\left(\mathrm{~s}, 18 \mathrm{H}, \mathrm{CH}_{2}, \mathrm{CH}_{3}-\mathrm{O}\right), 4.26\left(\mathrm{t}, J=6.20 \mathrm{~Hz}, 4 \mathrm{H}, \mathrm{CH}_{2}-\mathrm{O}\right), 6.57(\mathrm{~d}, J=2.8 \mathrm{~Hz}, 2 \mathrm{H}, \mathrm{PhH}), 6.58(\mathrm{~d}, J \\
=2.62 \mathrm{~Hz}, 2 \mathrm{H}, \mathrm{PhH}), 6.98(\mathrm{~s}, 2 \mathrm{H} \mathrm{PhH}), 8.09(\mathrm{~s}, 2 \mathrm{H}, \mathrm{N}=\mathrm{CH}), 12.12(\mathrm{~s}, 2 \mathrm{H}, \mathrm{OH})\end{array}$ \\
\hline
\end{tabular}

consistent with the elemental analytical results and the synthesized Salamo-type bisoxime compounds $\mathrm{H}_{2} \mathrm{~L}^{1}-\mathrm{H}_{2} \mathrm{~L}^{3}$ is the target compounds. The ${ }^{1} \mathrm{H}$ NMR spectra showed a singlet at about 8.09-8.17 ppm indicating the existence of oxime bonds ${ }^{12}$.

\section{Conclusion}

Three new Salamo-type compounds $\mathrm{H}_{2} \mathrm{~L}^{1}-\mathrm{H}_{2} \mathrm{~L}^{3}$ that have two oxime bonds instead of imine bonds have been designed and synthesized by the reaction of 2 equivalents of 2-hydroxy4-methoxybenzaldehyde with 1,5-bis(aminooxy)pentane, 1,6bis(aminooxy)hexane or 1,9-bis(aminooxy)nonane in hot ethanol medium, respectively. The structures of the Salamotype bisoxime compounds $\mathrm{H}_{2} \mathrm{~L}^{1}-\mathrm{H}_{2} \mathrm{~L}^{3}$ have been analyzed by EA, IR spectra and ${ }^{1} \mathrm{H}$ NMR spectroscopy. The Salamo-type bisoxime compounds may be promising units for the construction of supramolecular metal complexes and have reference for the further investigation.

\section{REFERENCES}

1. H.L. Wang, D.P. Zhang, Z.H. Ni, X.Y. Li, L.J. Tian and J.Z. Jiang, Inorg. Chem., 48, 5946 (2009).

2. J.K. Karjalainen, O.E.O. Hormi and D.C. Sherrington, Tetrahedron Asymm., 9, 3895 (1998).

3. H. Chen and J. Rhodes, J. Mol. Med., 74, 497 (1996).

4. A. Iqbal, H.L. Siddiqui, CM. Ashraf, M.H. Bukhari and C.M. Akram, Chem. Pharm. Bull. (Tokyo), 55, 1070 (2007).

5. S.T. Girousi, E.E. Golia, A.N. Voulgaropoulos and A.J. Maroulis, Fresenius J. Anal. Chem., 358, 667 (1997).

6. M.N. Desal, P.O. Chauhan and N. Shan, Eur. Symp. Corrision Inhibitors, 27, 891 (1995).

7. S. Akine, T. Tadokoro and T. Nabeshima, Inorg. Chem., 51, 11478 (2012).

8. W.K. Dong, X.N. He, H.B. Yan, Z.W. Lv, X. Chen, C.Y. Zhao and X.L. Tang, Polyhedron, 28, 1419 (2009).

9. W.K. Dong, C.Y. Zhao, Y.X. Sun, X.L. Tang and X.N. He, Inorg. Chem. Commun., 12, 234 (2009).

10. S. Akine, T. Taniguchi, W. Dong, S. Masubuchi and T. Nabeshima, J. Org. Chem., 70, 1704 (2005).

11. J.A. Faniran, K.S. Patel and J.C. Bailar Jr., J. Inorg. Nucl. Chem., 36, 1547 (1974).

12. S. Akine, T. Taniguchi and T. Nabeshima, Chem. Lett., 30, 682 (2001). 